\title{
Aluminum Nitride Wide Band-gap Semiconductor and Its Basic Characteristics
}

\author{
Xinru Fu \\ North China Electric Power University, Beijing, China \\ xinruF@163.com
}

Keywords: Aluminum nitride; Band-gap semiconductor; Characteristic; Production; Application

\begin{abstract}
Aluminum nitride is wide and direct band gap compound semiconductor material. High temperature strength, good thermal conductivity, small thermal expansion coefficient, strong corrosion resistance, good dielectric properties and other characteristics make aluminum nitride as impact resistance material, crucible materials, and conductive materials widely applied in various fields. This paper reviews the production method of aluminum nitride powder and its application in different fields.
\end{abstract}

\section{Introduction}

Aluminum nitride is a ceramic insulator, a third-generation semiconductor material. Aluminum nitride in the band gap at room temperature is $6.42 \mathrm{eV}$, thermal expansion coefficient of $4.5 \times$ $10-6^{\circ} \mathrm{C}$; the maximum stable to $2200{ }^{\circ} \mathrm{C}$ [1-4].This paper describes the basic characteristics of aluminum nitride based on aluminum nitride powder production method and its application in various fields.

\section{Basic Structure and Properties of Aluminum Nitride}

Comparisons of aluminum nitride and other materials are shown in Table 1. Compared with other materials, it can be seen that the melting point of aluminum nitride is higher, the coefficient of thermal conductivity is larger and the band gap is wider. These characteristics are caused by the internal structure of the special aluminum nitride.

Table 1 High and low settings of predictor variables

\begin{tabular}{|c|c|c|c|}
\hline & Thermal conductivity & Melting point & Band gap \\
\hline $\mathrm{AlN}$ & $210[\mathrm{~W} /(\mathrm{m} \cdot \mathrm{K})]$ & $2200\left[{ }^{\circ} \mathrm{C}\right]$ & $6.24[\mathrm{eV}]$ \\
\hline $\mathrm{AsGa}$ & $56[\mathrm{~W} /(\mathrm{m} \cdot \mathrm{K})]$ & $1238\left[{ }^{\circ} \mathrm{C}\right]$ & $1.4[\mathrm{eV}]$ \\
\hline $\mathrm{GaN}$ & $130[\mathrm{~W} /(\mathrm{m} \cdot \mathrm{K})]$ & $1700\left[{ }^{\circ} \mathrm{C}\right]$ & $3.4[\mathrm{eV}]$ \\
\hline
\end{tabular}

Aluminum nitride is connected by covalent bonds. Fig. 1 shows the crystal structure of aluminum nitride. It has a hexagonal crystal structure, which is the same as zinc sulfide and zinc sulfide ore. Aluminum nitride space group is P63mc [5]. Its spatial structure led aluminum nitride has a high thermal stability, so that it should take before pressing and welding to produce industrial-grade material. 


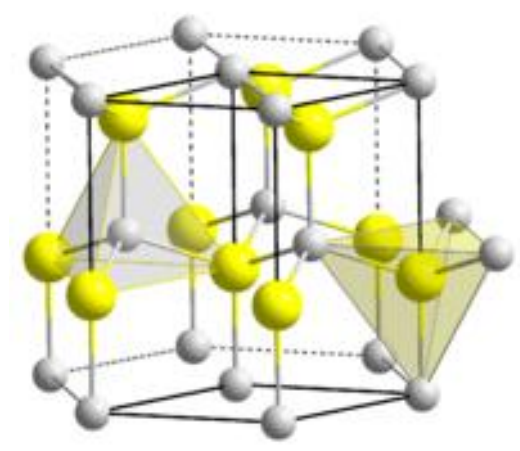

Figure 1. Crystal structure of aluminum nitride

Band-gap at room temperature of aluminum nitride is $6.42 \mathrm{eV}$, which belongs to direct band-gap semiconductor [6]. The minimum value of its valence band and the maximum of its conduction band are located on the origin of the $\mathrm{K}$ space, when the electron from the valence band to the conduction band, only need to change the energy on, without changing the electron quasi-momentum, which leads to the efficient transport of electrons, making aluminum nitride for light-emitting devices or other optoelectronic devices.

\section{Preparation Method of Aluminum Nitride}

Since aluminum nitride has good physical and chemical properties, it has been widely favored by science, but because of its higher processing costs, method of manufacturing aluminum nitride will also continue to develop.

Direct Nitriding Method. Aluminum nitride as the earliest methods: a nitrogen atmosphere at a high temperature of $800^{\circ} \mathrm{C} \sim 1200{ }^{\circ} \mathrm{C}$ [7], aluminum powder and aluminum nitride powder directly generate nitrogen compound. Chemical equation as Eq.1.

$$
\mathrm{Al}+\mathrm{N}_{2} \rightarrow \mathrm{AlN}
$$

This method is simple and suitable for mass production, has been widely used in industry. However, since the reaction is difficult to control, the aluminum nitride powder lumps is easily formed [8], thereby inhibiting the reaction, it is difficult to process the aluminum nitride powder of high purity.

CarbothermalReduction. Carbothermal reduction means that the reaction occurs at high temperature by reducing metallic aluminum and nitrogen. Chemical equation as Eq.2.

$$
\mathrm{Al}_{2} \mathrm{O}_{3}+3 \mathrm{C}+\mathrm{N}_{2} \rightarrow \mathrm{AlN}+\mathrm{CO}
$$

Carbon reduction method is advantageous in that the synthesized product fine granularity, wide material source, low cost, suitable for mass production. The disadvantage is that long production cycle, low efficiency, low production out of the purity of the product, easy to form metal carbides.

Self-Propagating High-temperature Synthesis (SHS). SHS originated in Russia [9], themethod is the use of external heat source to ignite an aluminum powder in high-pressure nitrogen gas by high chemical reaction heat between aluminum and nitrogen so that the reaction since maintained until the complete conversion of aluminum becomes aluminum nitride. The reaction is shown in Eq.3, wherein $\mathrm{X}$ is a diluent.

$$
\mathrm{Al}+\mathrm{N}_{2}+\mathrm{X} \rightarrow \mathrm{AlN}
$$

Regard to the preparation of aluminum nitride powder synthesized a synthetic short time, low energy consumption and many of the traditional methods cannot match advantage. It attracted the attention of all walks of life areas. 
Electrical Explosion Method. Electrical explosion method is able to extract high-purity aluminum nitride methods emerged in recent years [10].Studies have shown that, under 34KV power supply voltage and capacitance of $1.6 \mu \mathrm{F}$ storage conditions, high purity nitrogen as working gas, the pressure in the product range of $0.25 \sim 1.50 \mathrm{Mpa}$ prepared for nano-aluminum nitride and nano-aluminum mixtures.

\section{Application of Aluminum Nitride}

Aluminum nitride has a wide band-gap width, the stable crystal structure, good dielectric characteristics and the like so that it has been widely used.High purity aluminum nitride powder is the main raw material to manufacture high thermal conductivity of the aluminum nitride ceramic substrate.

The aluminum nitride ceramic substrate, high thermal conductivity, low coefficient of expansion, high strength, high temperature, chemical resistance, high resistivity, low dielectric loss, is the ideal LSI heat dissipation board and packaging materials[11].Aluminum nitride has high hardness characteristics, is the new wear-resistant ceramic material that can be used badly worn parts [12].The use of aluminum nitride ceramic heat melt erosion resistance and thermal shock resistance can be made GaAs crystal crucible, aluminum evaporating dish, MHD power generation equipment corrosion and high temperature turbine components [13].Use of its optical properties can be used for infrared window. Aluminum nitride film can be made high-frequency piezoelectric elements, VLSI substrate or the like.Aluminum nitride is non-toxic, better performance of its metalized ceramic can replace toxic oxidation-sensitive porcelain is widely used in the electronics industry.

\section{Summary and Outlook}

Although the aluminum nitride in various areas has had excellent properties, but the distance scale, generalized development is still a long distance.There are two main reasons.

In the preparation of high purity alumina. Due to the manufacturing process constraints, difficult to synthesize short growth cycle, high-precision, low-cost, large-scale aluminum nitride powder. This makes the price of aluminum nitride bottleneck expensive, even in its application to study more, but limits the processing of large-scale use of aluminum nitride. Synthesis of superior quality silicon nitride will be a trend of the future direction of technology development.

The oxidation of aluminum nitride.Exposed to the air increases the oxygen content of aluminum nitride, it is necessary when producing aluminum nitride powder and then its surface modification.

We need to seize the pulse of the times, through scientific and technological progress and constantly improve the processing technology of aluminum nitride, aluminum nitride expand the application level.

\section{References}

[1] W Mori and STakamizawa:Journal of Solid State Chemistry; Vol.152 (2000) No.1, p.120-p.129.

[2] Y.J.Zhang; Z.F.Wang and W.J.lv: Materials Review; Vol.11(1997) No.3, p.52-p.56 (Language: In Chinese).

[3] Y.P.Ye; Y.Sun and Z.X.Gao: Chemical Engineering Progress; Vol.11(1996) No.1, p.15-p.19. (Language: In Chinese)

[4] SheppardLM.Aluminumnitride and Aversatilebutchallenging: The Society;Vol.11(1990) No.1, p641-p642.

[5] Information

on http://baike.baidu.com/link?url=JaHjyzW10UhyvCVsb0b210YXi3RCeUZSD6wXAuMECmQ DNE9ZGM99mcTWNsltERc4OEgmJUTT_mL2gsmTaBY7gq. 
[6] Donald A.Neamen: An Introduction to Semiconductor Devices (Tsinghua University Press, China 2006), p.55.

[7] RadwanM and BahgatM:Packaging\&Production; Vol.36 (1996) No.8; p.81.

[8] W.W.Wang; R.Z.Cheng; X.Y.Hu; Y.J.Zhang; P.X.Song; Y.T.Tian and J.X.Li:Science and EngineeringMaterials; Vol.29 (2011) No.2; p.3 (Language: In Chinese).

[9] Y.Jiang; Z.J.Kang; Y.F.Xie;Y.Xia and H.Lv: Rare metals;Vol.1 (2013) No.3; p.2(Language: In Chinese).

[10]H.P.Wang and S.Q.Xu: Simulation and Application of Composite Ceramic Tool Materials Low Temperature Sintering of thermal conductivity and high thermal conductivity aluminum nitride ceramics (MS., China Institute of Metrology, China 2012), p.28(Language: In Chinese).

[11]L.Zhen:Growth and surface nitriding aluminum metallization process(MS., Shanghai University, China 2014), p.5(Language: In Chinese).

[12]B.Zhan:Microstructure and Properties of Ceramic cutting tool behavior and ultrafine grain Ti (C, N) metal(Ph.D., Hefei University of Technology, China 2013), p.3-p.30(Language: In Chinese).

[13]G.H.Wang:Preparation and Properties of AlN / Al-Si composites(MS., Xi'an University of Technology, China 2005), p.10(Language: In Chinese).

[14]J.Lin:Preparation and properties of nano-carbon composite thermal interface material(MS., Guangdong University of Technology, China 2011), p.34-p.51 (Language: In Chinese). 